\title{
Pneumocephalus complicating frontal sinus osteoma
}

S Simarak
B Suraprasit
MD
A Senatham
MD
Department of Radiology, Chiang Mai
University, Thailiand

\section{Abstract}

Pneumocephalus is most frequently caused by head trauma, especially to the paranasal sinuses and mastoid areas. Tumours of the skull base, such as osteoma or pituitary tumour, are less common causes. Since osteoma is one of the more common benign tumours of the nose and paranasal area with the frontal sinus being its most frequent location, special attention should be paid to the examination of this area for frontal osteoma in patients presenting with spontaneous pneumocephalus.

\section{Introduction}

Pneumocephalus is defined as an intracranial gas collection in the extradural, subdural, subarachnoid, intraventricular or intracerebral compartment. Head injury and cranial surgery were found to account for $74.5 \%$ of cases, followed by tumours in $12.9 \%{ }^{1}$ The majority of tumours implicated in pneumocephalus are sinus osteomas. Although an osteoma is considered to be a benign tumour, it can demonstrate a slow growth pattern and may result in intracranial complications such as that demonstrated in our patient.

\section{Case report}

A previously healthy 43-year-old man presented with a two-year history of right-sided headache and weakness of his left extremities. He was first admitted in December 1995 with right temporal and occipital headache for two weeks, followed by sudden weakness of the left upper and lower extremities one week later. Cranial computed tomography (CT) scan demonstrated a large subdural pneumocephalus in the right superior frontal region. Frontal osteoma was however not recognized at this examination (Figure 1). The patient refused

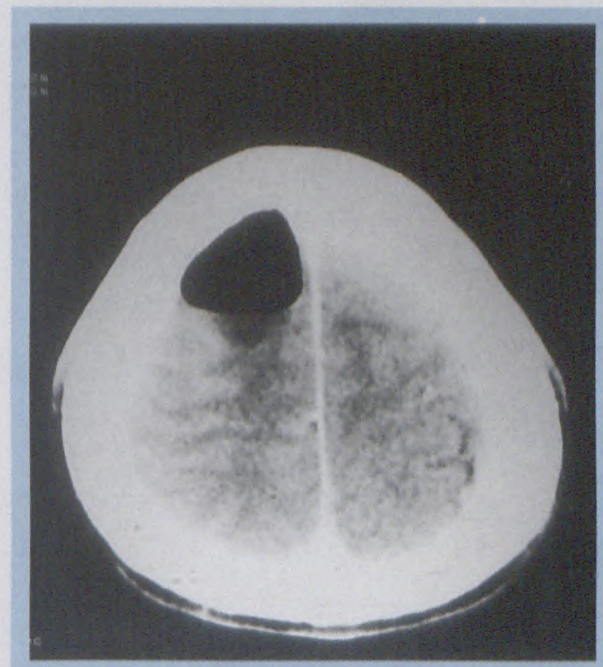

Figure 1: Cranial computed tomography demonstrating a large subdural pneumocephalus in the right superior frontal region. 


\section{Pneumocephalus complicating frontal sinus osteoma}

\section{from page 29}

proper treatment and was discharged with the clinical diagnosis of intracranial abscess. The patient still had headache and weakness of left extremities during the interval and was readmitted in December 1997 - but again refused surgery and was discharged. Because of aggravation of his symptoms with additional focal seizure of his left extremities, he was admitted again in April 1998. The motor power of his upper and lower extremities gradually decreased until he was unable to walk.

Skull radiographs demonstrated a large subdural air collection in the right superior fronto-parietal region (Figure 2). Cranial CT scan during the
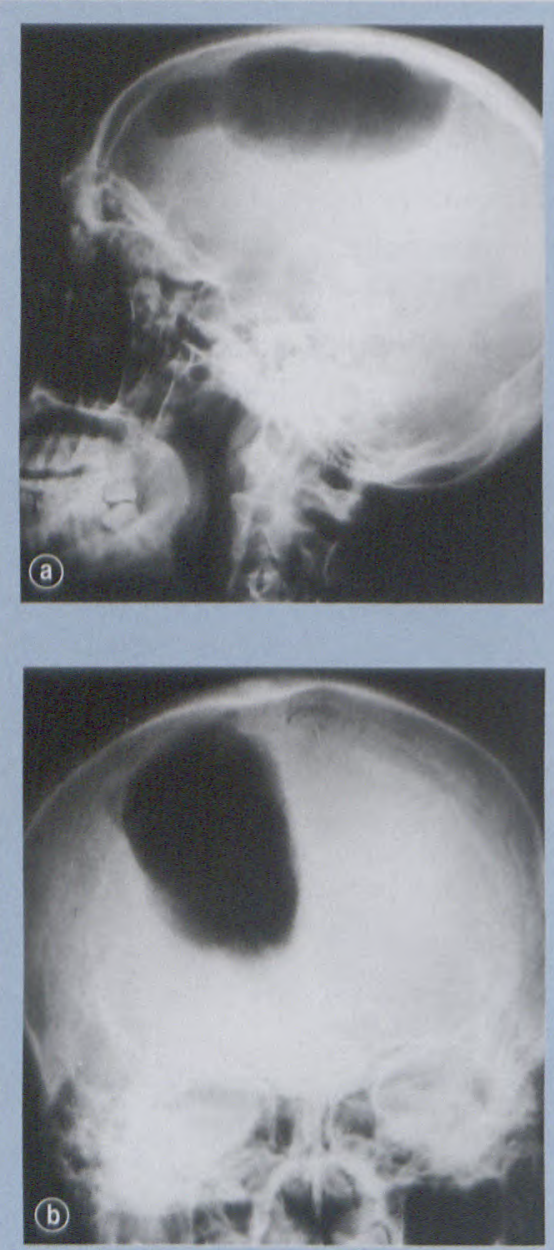

Figure 2: Skull radiographs demonstrating a large subdural air collection in the right superior fronto-parietal region.

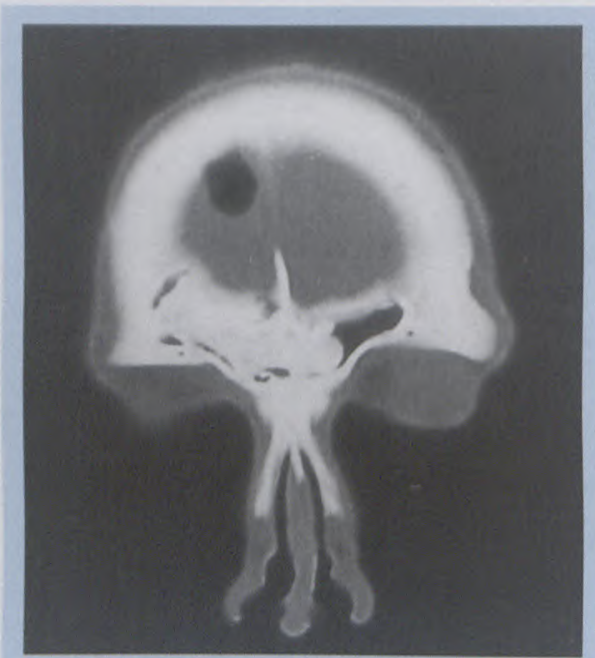

Figure 3: Cranial computed tomography at last admission confirms the presence of subdural air at the right superior frontal region, and also reveals a large osteoma occupying most of the frontal sinus with extension to the left.

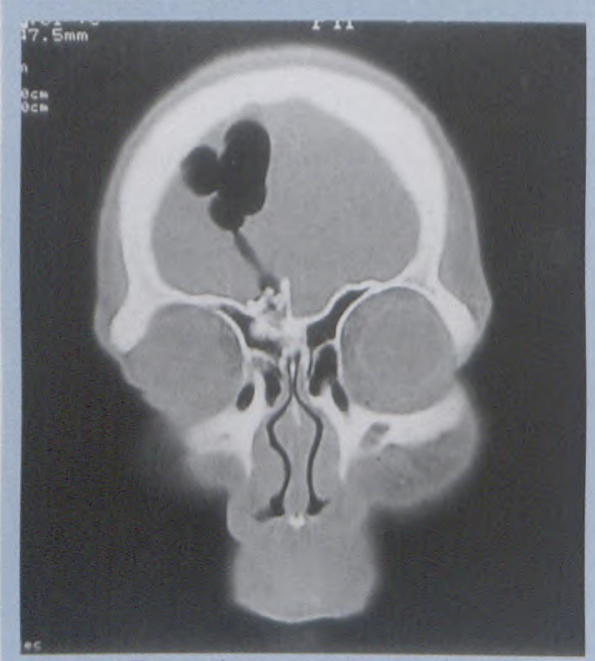

Figure 4: Tumour fragments shown in the cranial cavity, with tracking of air from the frontal sinus to the subdural air collection.

most recent admission (Figure 3,4) confirmed the presence of subdural air and also demonstrated a large osteoma of the frontal sinus, with fragments of tumour in the cranial cavity and tracking of air from the frontal sinus to the subdural air collection. He finally had corrective surgery for removal of the osteoma and repair of dural defect with uneventful recovery.

\section{Discussion}

Although pneumocephalus is quite common following trauma to the paranasal sinus and mastoid areas, spontaneous pneumocephalus, on the contrary, is quite rare. One cause of spontaneous pneumocephalus is the wellrecognized complication of osteoma of the paranasal sinuses which was first reported by Cushing in 1927.2

Osteoma of the paranasal sinuses is a histologically-benign neoplasm. The frontal sinus is the most frequent location, accounting for $75-80 \%$ of osteomas in the paranasal sinus region. ${ }^{3,4}$ The most common symptoms of osteon a are pain and headache, but many osteomas are asymptomatic and are discovered accidentally on sinus radiographs. Complications of osteoma are rare, but they may cause ocular or intracranial problems such as proptosis, meningitis, brain abscess, intracranial mucocoeles or intracranial pneumocephalus. In spite of their benign nature, osteomas may grow slowly and extension of the lesion posteriorly can breach the dura mater, allowing air to enter the cranium leading to life-threatening complications.

Koivunen $\mathrm{et} \mathrm{al}^{4}$ studied the growth rate of osteomas of the paranasal sinuses in 44 patients. They found that the mean growth rate of 23 osteomas that were followed up (including 10 static tumours) was $0.91 \mathrm{~mm}$ per year, varying from 0 to $6.00 \mathrm{~mm}$ per year (SD 1.41) Of the 13 that were growing, the mean growth rate was $1.61 \mathrm{~mm}$ per year. Spencer and Mitchell ${ }^{5}$ concluded from a follow-up study of frontal sinus osteomas over 17 years that the growth rate varies remarkably. Some were stable, while others may grow as much as $6 \mathrm{~mm}$ per year.

There are two characteristic histologic types of osteomas. The most common type is ivory or compact osteoma (composed of hard dense bone 


\section{from page 30}

with minimal fibrous tissue) and the other type is the spongy or fibrous osteoma (contained mature cancellous bone), which is less common.

The diagnosis of intracranial pneumocephalus and paranasal sinus osteoma can be easily made by radiographs as well as by CT scans. On radiography, paranasal sinus osteomas appear as round or oval, well circumscribed, highly radiopaque structures. They rarely attain a size larger than $2 \mathrm{~cm}$. The fibrous osteoma, however, appears less dense on radiographs and thus may be confused with a cyst. CT scans demonstrate a homogenous hyperdense mass arising within a sinus cavity. Radionuclide scanning with a bone agent usually demonstrates an area of homogenously intense uptake. Shibata $e^{~}$ al $^{6}$ performed Magnetic Resonance Imaging in five patients with osteomas of the skull and found that all osteomas appeared as low signal intensity on T1W images. The T2W images correlated well with histological findings: dense osteomas showed homogenous low-intensity, while spongy osteomas had high signal intensity areas and mixed signal intensity corresponding to mixed spongy and dense osteoma.

The management of pneumocephalus due to paranasal sinus osteoma is surgical with removal of the tumour and repair of the dural defect. Opinions vary concerning the optimal management of paranasal sinus osteomas in the asymptomatic individual. Noyek et al ${ }^{7}$ performed radionuclide bone scans in frontal sinus osteomas and recommended surgery for patients with "hot" scans, while conservative and follow-up studies can be undertaken in "cold" lesions. Koivunen ${ }^{4}$ suggested that an osteoma in the paranasal sinus should be removed if it shows any sign of growth, if it fills more than $50 \%$ of the volume of the sinus or if it causes any symptoms. Rappaport et al ${ }^{8}$ also suggested removal of the tumour if it were located close to the nasolacrimal duct.

\section{Conclusion}

Although osteomas of the frontal sinus are benign histologically, they can cause serious intracranial complications. In complicated cases, surgery is indicated, while in asymptomatic lesions factors concerning the proper management have been suggested.

\section{Acknowledgements}

The authors wish to thank Prof Malai Muttarak and Prof Wilfred CG Peh for their advice, encouragement and review of the manuscript.

\section{References}

1. Markham F. The clinical features of pneumocephalus based upon a survey of 284 cases with report of 11 additional cases. Acta Neurochir, 1967; 16:1-78.

2. Cushing H. Experiences with orbitoethmoidal osteoma having intracranial complications. Surg Gynecol Obstet, 1927; 44: 721-742.

3. Montgomery WW. Osteoma of the frontal sinus. Ann Oto Rhinol Laryngol, 1960; 69: 245-255.

4. Koivunen P, Lopponen H, Fors AP, Jokinen $K$. The growth rate of osteomas of the paranasal sinuses. Clin Otolaryngol, 1997; 22: 111-114.

5. Spencer MG, Mitchelli DB. Growth of a frontal sinus osteoma. J Laryngol Otol, 1987; 95: 291-304.

6. Shibata Y, Matsumura A, Yoshii Y, Nose T. Osteoma of the skull: comparison of magnetic resonance imaging and histological findings. Neurol Med Chir (Tokyo), 1995; 35(1): 13-6.

7. Noyek AM, Chapnik JS, Kirsh JC. Radionuclide bone scan in frontal sinus osteoma. Aust NZJ Surg, 1989; 59: 127-132.

8. Rappaport JM, Attia EL. Pneumocephalus in frontal sinus osteoma: a case report. Otolaryngol, 1994; 23: 430-436.

\section{British Journal of Radiology Web site}

$\mathrm{T}$ he British Institute of Radiology have recently announced the establishment of a Web site at http://www.bir.org.uk, allowing access to The British Journal of Radiology articles before they are published. This is primarily intended for subscribers, but one can preview complete sample back issues at http://www.bir.org.uk/online/sample.html, or apply for a free three-month trial subscription. One is able to view complete articles with hyperlinks to figures and references. This site gives an excellent feel of what will be possible in the future, when more journals become available in electronic format on the Internet.

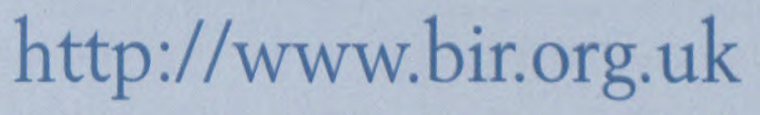

